systems ${ }^{9}$. Social scientists are examining the connections between wealth, population size or density and carbon emissions ${ }^{10}$, but not within realistic, economically constrained, engineered landscapes.

Translating urban carbon science into solutions requires two key steps. First, it must become 'operational'. Like weather stations, data and forecasting, the measurement, monitoring and modelling of urban carbon flows is a global need that is best accomplished collectively. This requires long-term collaborative funding and institutional support beyond the typical three-year research-grant cycle.

Second, an independent intergovernmental centre (with regional representation) is needed to ensure standardization and priority. This could be funded jointly by governments, foundations and intergovernmental institutions. Such an 'urban carbon solutions centre' must generate practical results, tools and carbonmitigation options with the involvement of community groups, mayoral staff and energy providers. Cities could pay the solutions centre to provide information tailored to their locale. Some work could be undertaken by the private sector.

With detailed knowledge of carbon flows, cities might succeed in reducing global emissions where nations have failed.

Kevin Robert Gurney is associate professor in the School of Life Sciences and the Global Institute of Sustainability, Arizona State University, Tempe, Arizona, USA. Paty Romero-Lankao, Karen C. Seto, Lucy R. Hutyra, Riley Duren, Christopher Kennedy, Nancy B. Grimm, Jim R. Ehleringer, Peter Marcotullio, Sara Hughes, Stephanie Pincetl, Mikhail V. Chester, Daniel M. Runfola, Johannes J. Feddema, Joshua Sperling.

e-mail:kevin.gurney@asu.edu

1. City of Los Angeles. ClimateLA: Municipal Program Implementing the GreenLA Climate Action Plan (City of Los Angeles, 2008).

2. World Bank. Cities and Climate Change: An Urgent Agenda (Int. Bank for Reconstr. and Dev. \& World Bank, 2010)

3. Seto, K. C., Güneralp, B. \& Hutyra, L. R. Proc. Natl Acad. Sci. USA 109, 16083-16088 (2012).

4. Erickson, P. \& Tempest, K. Advancing Climate Ambition: How City-Scale Actions Can Contribute to Global Climate Goals (Stockholm Environ. Inst., 2014).

5. McKain, K. et al. Proc. Natl Acad. Sci. USA 109, 8423-8428 (2012)

6. Gurney, K. R. Eos 94, 199-200 (2013)

7. Hutyra, L. R. et al. Earth's Future 2, 473-495 (2014).

8. Kort, E. A., Frankenberg, C., Miller, C. E. \& Oda, T. Geophys. Res. Lett. 39, L17806 (2012).

9. Chester, M. V. et al. Earth's Future 2, 533-547 (2014).

10.Marcotullio, P. J. et al. Earth's Future 2, 496-514 (2014).

Full author affiliations accompany this article online at go.nature.com/vpqnfb

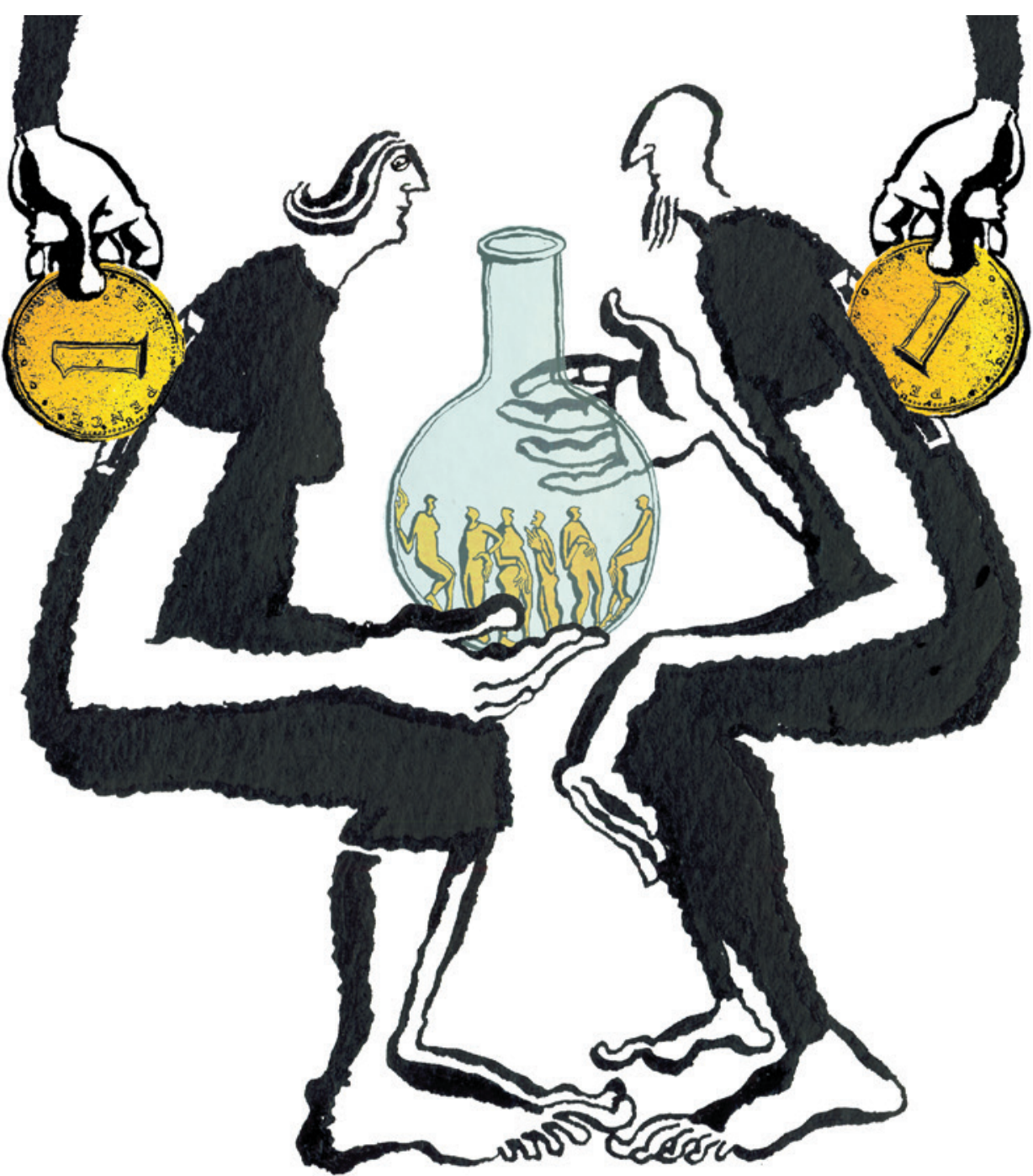

\title{
Women are funded more fairly in social science
}

\author{
UK data hold lessons for how to close the gender gap in \\ bioscience grant applications, success and size, argue \\ Paul Boyle and colleagues.
}

$\mathrm{D}$ espite the increasing commentary and debate on gender disparities in science ${ }^{1,2}$, equality will not be achieved without proactive support from key institutions.

One of the key drivers of academic inequality is the receipt of competitive grant funding. In the biomedical sciences, women get smaller grants than men in the United States ${ }^{3}$ and the United Kingdom ${ }^{4}$.

\section{DNATURE.COM}

For Nature's special issue on women in science, see:

nature.com/women
Similarly, figures from the European Research Council (ERC) for 2007-13 show that women make only one-quarter of grant applications, and they receive just one-fifth of awards. This pattern is evident at different rates across disciplinary domains: in the physical sciences and engineering, women submit $17 \%$ of grant applications and receive $15 \%$; in the life sciences, $30 \%$ and $21 \%$; and in the social sciences and humanities, 36\% and $31 \%$ (see go.nature.com/nqfvc3).

We find that UK social-science funding does not show such gender bias. When 


\section{CHECKING THE BALANCE}

Data from the United Kingdom's main

social-science funding body show little difference between female and male social scientists in application rate, success rate and grant size.

1

Overall grant applications and success

Men Women Application success

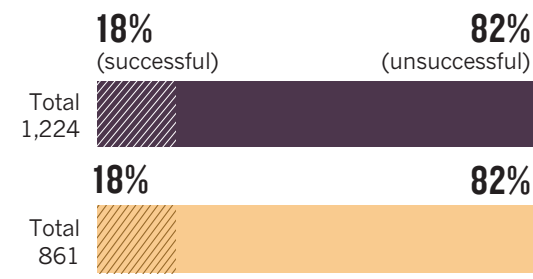

2 Grant applications with age

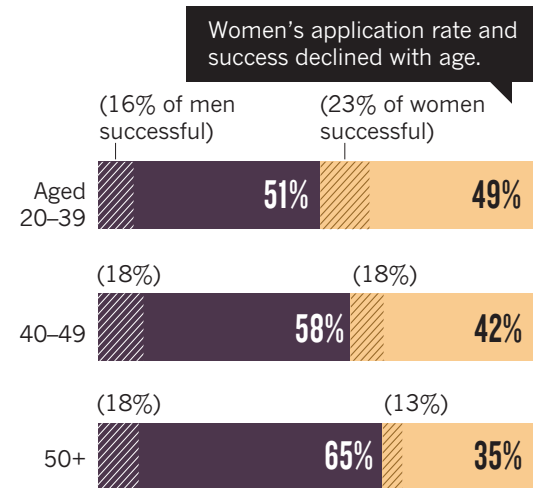

$\mathbf{3}$

Grant applications and awards by professional grade

Non-professors (readers, senior lecturers, lecturers, researchers)

(15\% of men $\quad$ (17\% of women successful) successful)

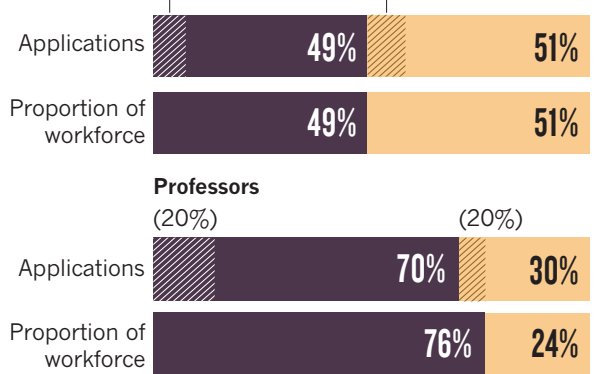

4

Amounts awarded

Median size of awarded grants

Non-professorial

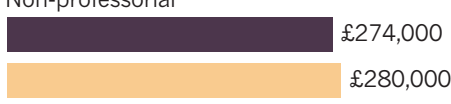

Professorial

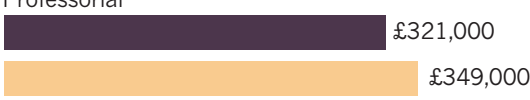

$£ 349,000$

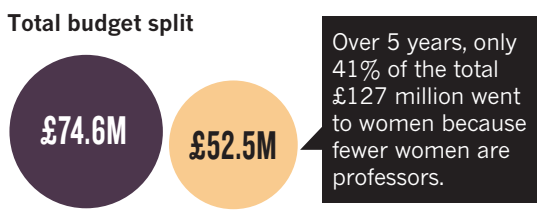

academic position is accounted for, in the data we present here there is little difference between female and male social scientists in application rate, success rate and grant size. We discuss some lessons that these results may hold for the biomedical sciences.

\section{WHO GOT WHAT?}

We considered applications to the UK Economic and Social Research Council (ESRC) Research Grants 'open call' scheme between 2008 and 2013 (one of us, P.B., was chief executive of the ESRC from 2010 to 2014). We examined whether women and men submitted a similar number of grants, and their respective success rates and sizes of awarded grants. We used the UK government's Higher Education Statistics Agency for data on numbers of men and women in social-science academic jobs in the United Kingdom. The results described here are underpinned by robust multivariate analyses.

We found that women were less likely than men to apply for grant funding (making up $41 \%$ of applications), even though there were only slightly fewer women (48\%) than men in social-science academic posts. But women and men were equally successful in winning ESRC grants (18\% success rate for both; see 'Checking the balance').

Women's application rates and funding success declined with age; men in all age groups had a similar success rate. Women under the age of 40 applied for as many grants as men in that age group, and were more successful. Women over 50 applied for fewer grants and were less successful than men in the same age group.

Comparing applications and success by academic position, we find that it is the smaller number of female professors that accounts for the overall difference in grant applications between men and women, and the greater success of older men. Male and female professors were equally successful, and women at lower grades were slightly more successful than men at the equivalent grade. Indeed, female professors were more likely to bid than their male counterparts: women made $30 \%$ of professorial applications, even though nationally only $24 \%$ of professorial posts were held by women.

The median amount awarded was not significantly different for women and men. On average, female professors won slightly larger amounts than male professors. However, over the five-year period, $59 \%$ of the $£ 127$ million (US\$198 million) allocated went to men, because fewer applications were received from women (recall that, accounting for academic position, those who applied for grants were equally successful).

The analyses we present are based on standard, routinely available data. Thus,

several caveats should be borne in mind These include: the difficulties of combining different data sources on staff eligible to apply for awards and actual applications; and a lack of further detailed information on applications, such as the number and gender of co-applicants.

Even so, there are clearly disciplinary differences in women's funding engagement and success. A comparison of figures from the UK Medical Research Council (MRC) and the

"Significant change is unlikely, without some bold re-structuring." ESRC shows that although the proportion of women in biomedical and social-science disciplines is similar (43\% and $45 \%$, respectively), the proportion of female grant applicants in $2012-13$ was $27 \%$ at the MRC and $42 \%$ at the ESRC (see go.nature. $\mathrm{com} /$ pesa2z). Furthermore, ESRC grants secured by female social scientists are of comparable size to those awarded to men. By contrast, at the Wellcome Trust ${ }^{4}$, a major UK biomedical-research charity, awards between 2000 and 2008 were on average around $£ 44,500$ (around 15\%) bigger for men than for women.

\section{DISRUPTING HIERARCHIES}

Whether these differences are a result of endemic discriminatory practices that discourage women from applying for awards - and for larger ones - in biomedical disciplines should be the focus of intense scrutiny.

It is interesting to consider why women may be better served in the social sciences. The positive consequences of higher levels of female representation in social-science disciplines include a move away from 'conventional gender expectations ${ }^{5}$ that align with hierarchical, individualistic and competitive behaviours. Social scientists have long been engaged with feminist researchmanagement practices, with the guiding principles of consultation, collaboration and social equality, which have disrupted male hierarchies ${ }^{6}$. Critiques of knowledge creation that exclude women as both researchers and participants have ensured that men in the social sciences have long been aware of the ingrained, institutionalized male culture of universities ${ }^{7}$ - an awareness that may be taking longer to permeate the science, technology, engineering and mathematics (STEM) disciplines.

Even so, the lack of women in professorial positions means that $59 \%$ of the total funds disbursed by ESRC between 2008 and 2013 in this study was allocated to men. Young female social scientists of today submit similar numbers of ESRC applications as equivalent men, are as successful and receive grants 


\section{BOLD ACTION}

\section{Ten ways institutions must close the gender gap}

\begin{abstract}
Steps for funding agencies worldwide - Commit to ambitious expectations for gender performance that link to eligibility for receiving awards, following the lead of the National Institute for Health Research. - Introduce targets for minimum gender representation on funding panels. - Train selection panels on gender-equality issues, including unconscious bias. - Submit data annually to independent scrutiny of gender differences in applications, success rates and award sizes.
\end{abstract}

- Publish figures to allow cross-agency and cross-national comparison by discipline.
Steps for universities worldwide - Publish gender breakdowns in key areas including promotions, appointments and rewards in a consistent way, allowing for cross-institution comparison; such transparency would allow prospective employees and students to assess the institutional culture.

- Embed gender-equality issues in work practice. Become beacons of good practice for public-sector and private employers. - Support women's career progression through the ongoing development of promotion criteria that focus on quality rather than quantity.

- Engage men in championing gender equality. Commit to the principles and uptake of shared parental leave.

- Celebrate women's achievements equally in a public way. of comparable size; it is quite possible that they will maintain this success as they age. Yet this is unlikely to transpire if women cannot access the more senior positions that men have dominated. And as these women rise through the ranks they will not experience the same work-life balance as men, the same child or parental care responsibilities, or the same cultural attitudes to the importance of their labour. Consequently, they will 웅 be more likely to have part-time or fixed岀 term contracts and to take career breaks.

In other words, young women perform well today, but they will continue to match men only if structural changes are implemented within universities and funding agencies (see 'Ten ways institutions must close the gender gap'). If the current pace of

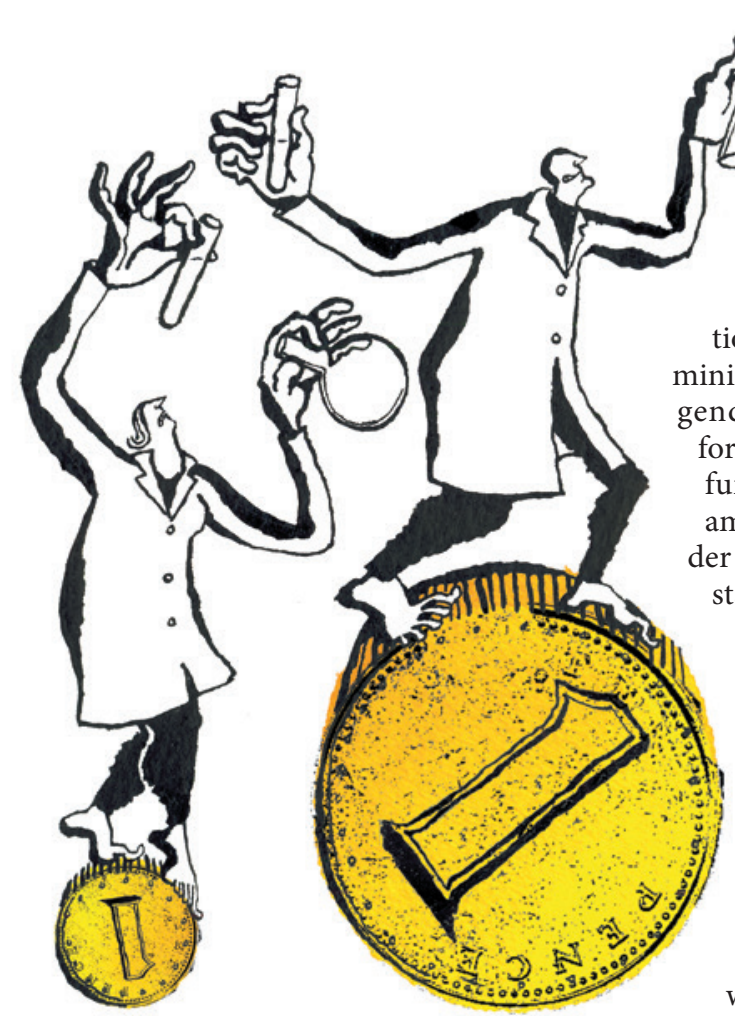

change continues, it will take 39 years for women to be represented equally among the UK professoriate - and this is likely to vary widely by discipline (see go.nature. com/gwihpt).

\section{SIGNS OF IMPROVEMENT}

It would be wrong to assume that nothing is being done. All seven UK research-funding councils, through Research Councils UK, have published expectations for themselves and for institutions in receipt of their funding, and these statements include an ongoing commitment to promoting cultural change in relation to equality and diversity. The Athena SWAN initiative provides a framework for addressing gender imbalances in biomedicine and has catalysed action - particularly since the National Institute for Health Research made attainment of an Athena SWAN silver award a requirement for certain large-scale funding.

Remarkable progress has been made elsewhere, most notably in Nordic countries. In Finland, for example, equality legislation introduced 20 years ago requires a minimum representation of $40 \%$ of either gender on any committee responsible for public spending, including research funders. Although controversial, even among some ardent proponents of gender equality, the rule has resulted in substantial change. By 2010, women made up $50 \%$ of the board of the Academy of Finland and of the country's scientific committees.

Despite such signs of improvement, gender inequality along the science-career trajectory continues to be pervasive. Men earn more than women ${ }^{8}$; academics who are mothers are less likely to be promoted and have lower salaries than women who do not have children ${ }^{9}$; and
'Brian' is more likely to be hired than 'Karen' as a professor, even if they have identical applications ${ }^{10}$. Consequently, there are fewer women in senior professorial, administrative and university-president roles. Although women make up $47 \%$ of non-professorial higher-education positions in the United Kingdom, they account for less than $20 \%$ of professorial appointments.

Significant change is unlikely, without some bold re-structuring. Bringing together funding agencies and a consortium of prominent universities who have shown commitment to these issues to develop coordinated approaches could have a significant impact. Organizations such as Science Europe and the Global Research Council, which have already committed to helping to reduce gender inequalities in science, should lead the way.

Paul J. Boyle is president and vicechancellor of the University of Leicester, UK. From 2010 to 2014, he was chief executive of the United Kingdom's Economic and Social Research Council. Lucy K. Smith is a senior research fellow, Nicola J. Cooper is professor of health-care evaluation research, and Kate S.Williams is a senior research fellow in the Department of Health Sciences, University of Leicester, UK. Henrietta O'Connor is professor in the Department of Sociology, University of Leicester, UK.

1. Nature 522, 255 (2015)

2. Shen, H. Nature $495,22-24$ (2013).

3. Reineke Pohlhaus, J. et al. Acad. Med. $\mathbf{8 6}$ 759-767 (2011).

4. Bedi, G., Van Dam, N. T. \& Munafo, M. Lancet 380,474 (2012).

5. Glass, J. L. et al. Soc. Forces 92, 723-756 (2013).

6. Mauthner, N. S. \& Edwards, R. Gender Work Organ. 17, 481-502 (2010).

7. Morgan, D. in Doing Feminist Research (ed. Roberts, H.) Ch. 4 (Routledge and Kegan Paul, 1981).

8. Moss-Racusin, C. A. et al. Proc. Natl Acad. Sci. USA 109, 16474-16479 (2012).

9. Correll, S. J., Benard, S. \& Paik, I. Am. J. Sociol. 112, 1297-1339 (2007).

10.Steinpreis, R. E., Anders, K. A. \& Ritzke, D. Sex Roles 41, 509-528 (1999). 